\title{
Parameters of ovarian reserve in relation to urinary concentrations of parabens
}

\author{
Joanna Jurewicz ${ }^{1 *}$, Michał Radwann ${ }^{2,3}$, Bartosz Wielgomas ${ }^{4}$, Anetta Karwacka ${ }^{5}$, Anna Klimowska ${ }^{4}$, Paweł Kałużny ${ }^{1}$,
} Paweł Radwan² and Wojciech Hanke ${ }^{1}$

\begin{abstract}
Background: Parabens are synthetic chemicals commonly used in cosmetics, pharmaceuticals, food and beverage processing as antimicrobial preservatives. In experimental animals, parabens exposure was associated with adverse effects on female reproduction. Despite the widespread use of parabens little is known about their effect on female fecundity. The objective of the current analysis was to evaluate the associations of urinary parabens concentrations with parameters of ovarian reserve among women undergoing treatment in a fertility clinic.

Methods: Five hundred eleven female aged 25-39years who attended the infertility clinic in central region of Poland for diagnostic purposes were recruited between September 2014 and February 2019. Urinary concentrations of parabens were measured by a validated gas chromatograohy ion-tap mass spectrometry method. Parameters of ovarian reserve were: antral follicle count (AFC), anti-Müllerian hormone (AMH), follicle-stimulating hormone (FSH) and estradiol $\left(E_{2}\right)$ levels.

Results: The geometric mean of specific gravity adjusted urinary concentrations of methyl (MP), ethyl (EP), propyl (PP), butyl (BP) and izobutyl paraben (iBuP) were $107.93 \mu \mathrm{g} / \mathrm{L}, 12.9 \mu \mathrm{g} / \mathrm{L}, 18.67 \mu \mathrm{g} / \mathrm{L}, 5.02 \mu \mathrm{g} / \mathrm{L}$ and $2.80 \mu \mathrm{g} / \mathrm{L}$. Urinary concentrations of PP in the third quartile of exposure ((50-75] percentyl) were inversely associated with antral follicle count ( $p=0.048)$, estradiol level $(p=0.03)$ and positively with FSH concentration $(p=0.026)$. MP, EP, BP and iBuP parabens were not associated any with parameters of ovarian reserve.

Conclusions: Chronic exposure to PP may potentially contributing to reduced fecundity and impair fertility. As this is one of the first study to investigate the potential effect of parabens on ovarian reserve further epidemiological studies with longer duration of observation are needed.
\end{abstract}

Keywords: Ovarian reserve, Parabens, Fertility, Environmental exposure

\section{Background}

Parabens are synthetic chemicals, esters of 4hydroxybenzoic acid widely used in cosmetics such as shampoos, moisture solutions, shaving gels, spray tanning solution, toothpaste, pharmaceuticals, food and beverage processing as antimicrobial preservatives because of their

* Correspondence: joanna.jurewicz@imp.lodz.pl

The work was done at the Nofer Institute of Occupational Medicine, Lodz, Poland.

${ }^{1}$ Department of Environmental Epidemiology, Nofer Institute of Occupational Medicine, 8 Teresy St, 91-362 Lodz, Poland

Full list of author information is available at the end of the article antibacterial and fungicidal properties [1]. Dermal absorption from personal care products, including lotions and cosmetics is considered to be a main route of parabens exposure [2], but exposure can occur also through ingestion and inhalation [2]. Parabens are popular because of their low toxicity and cost [3]. Parabens, estrogenic chemicals [3, 4] bind both estrogen receptor (ER)-alpha and (ER)-beta [5, 6]. The estrogenic activity of parabens increases with the length and branching of the alkyl chain $[7,8]$. Chen et al. (2007) and Darbre and Harvey (2008) $[9,10]$ have reported

(c) The Author(s). 2020 Open Access This article is licensed under a Creative Commons Attribution 4.0 International License, which permits use, sharing, adaptation, distribution and reproduction in any medium or format, as long as you give appropriate credit to the original author(s) and the source, provide a link to the Creative Commons licence, and indicate if changes were made. The images or other third party material in this article are included in the article's Creative Commons licence, unless indicated otherwise in a credit line to the material. If material is not included in the article's Creative Commons licence and your intended use is not permitted by statutory regulation or exceeds the permitted use, you will need to obtain permission directly from the copyright holder. To view a copy of this licence, visit http://creativecommons.org/licenses/by/4.0/ The Creative Commons Public Domain Dedication waiver (http://creativecommons.org/publicdomain/zero/1.0/) applies to the data made available in this article, unless otherwise stated in a credit line to the data. 
that parabens may also act as antiandrogens and may affect thyroid function $[8,11]$.

A few animal toxicity studies have reported adverse effect of parabens on female reproductive and endocrine function [8, 11, 12]. Vo et al. (2010) [8] found that prepubertal female rats treated orally with parabens had a decrease in ovarian weight (MP, isopropyl paraben (i$\mathrm{PP})$ ) and histopathological changes in the ovaries (MP, i$\mathrm{PP}, \mathrm{BP}, \mathrm{iBuP}$ ) such as a decrease in corpora lutea, an increase in number of cystic follicles and thinning of follicular cells as well as decrease serum estradiol levels. A decrease in ER- $\beta$ expression in the ovaries was observed in a study evaluating pregnant rats exposed to parabens [11]. On the other hand Kang et al. (2002) [12] did not observe effect on reproductive organ weights and histopatological abnormalities in female offspring.

Human data on the female reproductive health effects of paraben exposure are limited. To date only three studies have evaluated exposure to parabens and women reproductive potentials. One study assessed the ovarian reserve [13], and two evaluated fertilization rate, embryo quality, implantation and live births $[14,15]$. Smith et al. (2013) [13] observed a trend of lower AFC with increasing urinary PP level among 193 female patients from the Massachusetts General Hospital Fertility Center [13]. The next study performed in United States evaluate the associations of paternal urinary concentrations of MP, $\mathrm{PP}$ and BP in relation to reproductive outcomes among 218 couples from a fertility center. Decreased odds of live birth was observed only after exposure to MP [14]. On the other hand, in the study performed by MinguezAlarcon and co-workers (2016) [15], among 245 women undergoing infertility treatments, urinary concentrations of MP, PP, BP were not associated with IVF outcomes specially total and mature oocyte count, proportion of high embryo quality, fertilization and implantation rate, clinical pregnancy and live births [15].

This study adds to the previous human studies of parabens exposure more statistical power, by larger study subjects and by assessment of exposure in two urine samples, which in case of nonpersistant chemicals is important. Additionally, exposure to five different parabens (MP, EP, $\mathrm{PP}, \mathrm{BP}, \mathrm{iBu}-\mathrm{P})$ were assessed.

The aim of this study was to determine whether the environmental exposure to parabens affects female ovarian reserve, one of the predictor of female fecundity among women undergoing treatment in a fertility clinic.

\section{Methods}

\section{Study participants and data collection}

The study population consists of 511 females aged 2539 years attending infertility clinic in central region of Poland for diagnostic purposes, because of couples' infertility (the failure to achieve a clinical pregnancy after
12 months or more of regular unprotected sexual intercourse) [16] between September 2014 and February 2019.

Only menstruating women who have confirmed ovulatory cycles without clinical co-existing chronic diseases that may reduce ovarian reserve (eg, adrenocortical insufficiency, abnormal karyotype, fragile $\mathrm{X}$ syndrome) were eligible for the study. Exclusion criteria included: spontaneous premature ovarian failure, previous surgical treatment of the ovaries, chemotherapy or pelvic radiotherapy (conditions that may lead to reduction of ovarian reserve), cysts in the ovaries including endometriates (excluding functional cysts) and conditions with no ovulatory cycles such as polycystic ovary syndrome, hypogonadotropic hypogonism, hyperprolactinemia.

The Nofer Institute of Occupational Medicine Bioethical Committee Board approved the study and written informed consent was obtained from all subjects before their participation.

All participants were interviewed and provided a blood and urine samples during their office visit. The information about demographics, socio-economic status, stress (life and occupational stress), medical history, lifestyle factors (smoking, alcohol consumption, diet, physical activity) and occupational exposures (physical and chemical exposure) were collected using nurse-administrated questionnaire at entry into the study.

\section{Assessment of ovarian reserve parameters}

The female ovarian reserve was assessed by AFC, concentration of hormones: AMH, FSH and $E_{2}$.

The AFC was measured in both ovaries in accordance with the recommendations of Broekmans et al. (2010) [17] only by certified specialist in the field of ultrasound in gynecology, trained in the evaluation of AFC. All tests were carried out at the beginning of the follicular phase, usually between 2 and 4 days of the cycle. Antral follicles with dimensions of 2 to $10 \mathrm{~mm}$ were considered for the assessment. The sum of antral follicles from the left and right ovaries was used for the analysis [18].

The intravenous blood sample was drawn and the serum was analysed for AMH with an enzyme linked immunoabsorbent method utilizing commercially available Gen-II ELISA kits according to manufacturer instruction (Beckman Coulter, Inc., USA). The FSH, and $E_{2}$ were measured using enhanced chemiluminescence method for VITROS ECi Immunodiagnostic System with MicroWell technology utilizing commercially available VITROS Reagent Packs and the VITROS Calibrators for the hormones according to manufacturer instruction (Ortho-Clinical Diagnostics Johnson \& Johnson, UK).

No fertility medications were used in the cycles proceeding assessment of ovarian reserve parameters.. 


\section{Urinary parabens measurements}

A convenience urine sample was collected in sterile polypropylene cup from each subject at the time of recruitment and from subsets of the study population $(N=120)$ at subsequent visits during infertility treatment cycles. Second urine sample was collected to confirm that exposure to parabens is habitual. Women with the second urine sample collected were not different $(p>$ 0.05 ) from the whole study population in terms of exposure to parabens, and characteristics (age, past diseases, alcohol consumption, duration of infertility) that may be associated with parameters of ovarian reserve.

After measuring specific gravity (SG) using a handheld refractometer the urine samples were frozen at $-20^{\circ} \mathrm{C}$ and sent to the laboratory in Department of Toxicology, Medical University of Gdańsk. Parabens were analyzed by GC-MS/MS method. The standard stock solutions (1 $\mathrm{mg} / \mathrm{ml}$ ) of each paraben were prepared in acetonitrile. The stock solutions were used to prepare two separate working solutions: one for fortification of quality control urine samples and the other one for the calibration. All solutions were stored at $-20^{\circ} \mathrm{C}$ in the dark and were stable for at least 6 months described by Lu et al. (2015) [19] with some modifications. The method allows to evaluate the total concentration (free plus conjugated) of analyzed parabens in urine samples and was described previously [19]. Since, the major source of parabens to humans are cosmetic products, personnel handling urine samples was instructed to avoid paraben containing personal care products during the sample collection, sample preparation and analysis to minimize the risk of external contamination.

Briefly, three milliliters of urine sample were hydrolyzed with a mixture of $1 \mathrm{M}$ acetate buffer ( $\mathrm{pH} 5.0)$ and $\beta$ glucuronidase from Helix pomatia type HP-2. After deconjugation procedure, parabens were extracted using nhexane and methyl tert-butyl ether mixture $(3: 1, v: v)$, then the organic phase was separated and cleaned-up with PSA and anhydrous magnesium sulfate. The cleaned extract was evaporated to dryness under gentle stream of nitrogen, subsequently the dry residue was dissolved in $50 \mu \mathrm{l}$ of BSTFA:TMCS (99:1) and derivatized for $30 \mathrm{~min}$ at $40^{\circ} \mathrm{C}$. One microliter of final extract was injected into GC-MS system.

Analyses were performed using gas chromatograph (Varian GC-450) equipped with low bleed VF5-ms capillary column $(30 \mathrm{~m} \times 0.25 \mathrm{~mm} \times 0.25 \mu \mathrm{m}+10 \mathrm{~m}$ EZ-guard, Varian) and $1177 \mathrm{split} /$ splitless injector (isothermal condition: $\left.280^{\circ} \mathrm{C}\right)$. The oven column program was: $60^{\circ} \mathrm{C}(3$ $\min ), 60^{\circ} \mathrm{C}-140^{\circ} \mathrm{C}\left(120^{\circ} \mathrm{C} / \mathrm{min}\right), 140^{\circ} \mathrm{C}-290^{\circ} \mathrm{C}\left(17^{\circ} \mathrm{C} /\right.$ $\mathrm{min}), 280^{\circ} \mathrm{C}(13 \mathrm{~min})$. Tandem mass spectrometry (ion trap mass spectrometer, Varian 220-MS) was applied as detection method. For quantitative analysis the following precursor and daughter $\mathrm{m} / \mathrm{z}$ ions were used: 224 and 209,
177 for MP; 238 and 195, 209, 223 for EP; 210 and 195 for PP, iBuP as well as BP. Labeled analogs of MP, PP and BP were used as internal standards with ion transitions $\mathrm{m} / \mathrm{z}$ : 228 to 213, 197 and 180 for MP d4; 216 to 210 for PP ${ }^{13} \mathrm{C}_{6}$ and $\mathrm{BuP}{ }^{13} \mathrm{C}_{6}$. The underlined ions were utilized for quantitative analysis. We used urine fortified at three concentration levels: low (LQC), medium (MQC) and high (HQC) for in-house quality control of the analytical procedure. Daily analytical batch consisted of one blank urine sample, two LQC and MQC samples, one HQC sample, 40 real urine samples and two reagent blank samples (all reagents without urine) to control external contamination during sample processing. The between-day precision was below 20\% for all studied parabens. Westgard rules were applied to validate each batch.

The applied analytical procedure was fully validated during developing process. However, when series of real samples were analyzed validation was limited to calibration curve preparation and evaluation of within- and betweenday precision before processing target urine samples. The calibration curve was prepared as sequential dilution of working solution in the range of $0.5-1000 \mathrm{ng} / \mathrm{ml}$. Samples which concentration exceeded the highest point of calibration curve were reanalyzed using smaller volume of urine. The limit of detection for MP, EP and PP was $0.5 \mathrm{ng} / \mathrm{ml}$ and for $\mathrm{iBuP}$ and $\mathrm{BP} 1.0 \mathrm{ng} / \mathrm{ml}$ [20]. The within- and between-day imprecision was 20 and $8 \%$ for MP and EP and $5 \%$ for PP, iBuP and $\mathrm{BP}$, respectively.

\section{Statistical analysis}

Descriptive statistics for subjects grouped by demographic characteristics were calculated, along with the distributions of urinary parabens, and antral follicle count and reproductive hormone levels. Spearman correlation coefficient was used as nonparametric measure of associations between concentrations of different parabens. Multiple least squares linear regression models were used to quantify the associations of urinary parabens (explanatory variables) with antral follicle count and the concentrations of reproductive hormones as dependent variables.

Parabens concentrations $<$ LOD were assigned a value equal to LOD divided by the square root of two [21]. Urinary parabens concentrations $(\mu \mathrm{g} / \mathrm{L})$ were adjusted for SG (specific gravity) using the formula: $\mathrm{Pc}=\mathrm{P}[(1.016-1)$ / (SG-1)], where Pc is the SG-corrected paraben concentration $(\mu \mathrm{g} / \mathrm{L}), \mathrm{P}$ is the measured paraben concentration, and 1.016 is the median SG (specific gravity of the urine sample) level in the study population.

MP, EP, PP, BP were categorized into 4 groups, first one consisted of values below limit of detection (LOD) to 25th percentile value, second-greater than the 25th percentile value to the median, third greater than the median to 75 th percentile value, while the fourth group 
consisted of values greater than the 75th percentile. Additionally urinary concentrations of those parabens were presented as a continuous variables. Due to the high proportion of samples below the LOD in case of iBuP paraben concentrations were categorized as above and below LOD.

Multivariable linear regression was used to explore a relationship between urinary paraben concentrations and hormone levels and antral follicle count.

Inclusion of covariates in the multivariable regression models was based on biological and statistical consideration. The following covariates were considered as potential confounders: age (years), smoking (yes/no), BMI $\left(\mathrm{kg} / \mathrm{m}^{2}\right)$, initial infertility diagnosis. $\mathrm{R}$ statistical software (ver.3.5.1) was used for analysis [22].

\section{Results}

\section{Study population characteristics}

Demographic characteristics of the study participants are presented in Table 1. In summary, most women had higher $(75.34 \%)$ or secondary (21.14\%) education and were non smokers $(92.17 \%)$. The mean $( \pm \mathrm{SD})$ age and body mass index (BMI) were $33.30 \pm 3.69$ years and $23.18 \pm$ $3.80 \mathrm{~kg} / \mathrm{m}^{2}$ respectively. Most of the study females drank none or less than 1 drink per week (55.0\%). Duration of couple's infertility lasted mostly $>5$ years $(35.23 \%)$ and $3-$ 5 years $(29.55 \%)$. The initial infertility diagnosis was mostly male factor (37.8\%), followed by idiopathic infertility $(31.1 \%)$ and female factor $(28.57 \%)$ (Table 1$)$.

The mean $( \pm \mathrm{SD})$ value for antral follicle count was $12.73 \pm 8.94$. The mean level of reproductive hormones were $1.17 \pm 1.46 \mathrm{ng} / \mathrm{ml}$ for $\mathrm{AMH}, 6.38 \pm 2.18 \mathrm{IU} / \mathrm{l}$ for FSH and $93.74 \pm 16.63 \mathrm{pg} / \mathrm{ml}$ for $\mathrm{E}_{2}$ (Table 2).

\section{Parabens levels in urine}

Table 3 summarizes the unadjusted and adjusted urinary parabens concentrations in the first and second urine samples. In the first sample the parabens with the highest geometric mean concentration was MP $(92.68 \mu \mathrm{g} / \mathrm{L}$, $107.93 \mu \mathrm{g} / \mathrm{L}$ SG-adjusted) followed by PP $(16.20 \mu \mathrm{g} / \mathrm{L}$, $18.67 \mu \mathrm{g} / \mathrm{L}$ SG-adjusted), EP $(11.28 \mu \mathrm{g} / \mathrm{L}, 12.90 \mu \mathrm{g} / \mathrm{L}$ SGadjusted), BP $(4.70 \mu \mathrm{g} / \mathrm{L}, 5.02 \mu \mathrm{g} / \mathrm{L}$ SG-adjusted $)$ and $\operatorname{iBuP}(3.16 \mu \mathrm{g} / \mathrm{L}, 2.80 \mu \mathrm{g} / \mathrm{L}$ SG-adjusted).

The second urine sample was collected from 120 women. The highest geometric mean concentration was MP $(49.13 \mu \mathrm{g} / \mathrm{L}, 67.18 \mu \mathrm{g} / \mathrm{L}$ SG-adjusted) followed by PP $(9.14 \mu \mathrm{g} / \mathrm{L}, \quad 46.49 \mu \mathrm{g} / \mathrm{L} \quad$ SG-adjusted $), \quad$ EP $(5.71 \mu \mathrm{g} / \mathrm{L}$, $7.85 \mu \mathrm{g} / \mathrm{L} \quad$ SG-adjusted $), \quad B P(3.99 \mu \mathrm{g} / \mathrm{L}, 4.74 \mu \mathrm{g} / \mathrm{L} \quad$ SGadjusted). iBuP was not detected in the second urine samples (Table 4).

Examined parabens were highly correlated in the first urine samples: MP with EP, PP, BP $(p<0.001)$ and with $\operatorname{iBuP}(p=0.002)$. EP was significantly correlated with $\mathrm{PP}$, $\mathrm{BP}, \operatorname{iBuP}(p<0.001)$, PP with $\mathrm{iBuP}$ and $\mathrm{BP}(p<0.001)$
Table 1 Characteristics of the study population $N=511$

\begin{tabular}{|c|c|}
\hline Variables & N (\%) \\
\hline \multicolumn{2}{|l|}{ Education } \\
\hline Vocational & $18(3.52)$ \\
\hline Secondary & $108(21.14)$ \\
\hline Higher & $385(75.34)$ \\
\hline \multicolumn{2}{|l|}{ Age [years] } \\
\hline $24-30$ & $121(23.68)$ \\
\hline $31-39$ & $390(76.32)$ \\
\hline Mean \pm SD & $33.30 \pm 3.69$ \\
\hline \multicolumn{2}{|l|}{ BMI $\left[\mathrm{kg} / \mathrm{m}^{2}\right]$} \\
\hline$<18,5$ & $29(5.68)$ \\
\hline $18,5-24,9$ & $301(58.90)$ \\
\hline $25-29,9$ & $154(30.14)$ \\
\hline $30-40$ & $27(5.28)$ \\
\hline Mean \pm SD & $23.18 \pm 3.80$ \\
\hline \multicolumn{2}{|l|}{ Smoking } \\
\hline No & $471(92.17)$ \\
\hline Yes & $40(7.83)$ \\
\hline \multicolumn{2}{|l|}{ Initial infertility diagnosis } \\
\hline Male factor & $193(37.8)$ \\
\hline Idiopathic & $159(31.1)$ \\
\hline Female factor & $146(28.6)$ \\
\hline Ovulation disorders & $62(12.1)$ \\
\hline Tubal factor & $24(4.7)$ \\
\hline Uterine factor & $8(1.6)$ \\
\hline Endometriosis & $52(10.2)$ \\
\hline Missing data & $13(2.5)$ \\
\hline \multicolumn{2}{|c|}{ Duration of couple's infertility [years] } \\
\hline $1-2$ & $39(7.63)$ \\
\hline $2-3$ & $141(27.59)$ \\
\hline $3-5$ & $151(29.55)$ \\
\hline$>5$ & $180(35.23)$ \\
\hline \multicolumn{2}{|l|}{ Alcohol use } \\
\hline None or $<1$ drink/week & $281(55.0)$ \\
\hline 1-3 drinks /week & $224(44.0)$ \\
\hline Everyday & $6(1)$ \\
\hline
\end{tabular}

and $\mathrm{BP}$ with $\mathrm{iBuP}(p<0.001)$. In the second urine sample the MP was highly correlated with EP, PP $(p<0.001)$ and $\mathrm{BP}(p=0.004)$. EP was significantly correlated with PP $(p<0.001)$. Whereas no statistically significant correlations was observed between EP and BP $(p=0.09)$ and PP and BP $(p=0.17)$ (Table 4).

There was a significant correlation between MP, EP and PP in the first and second urine sample (Table 5). Only in case of BP there was not significant correlation in both urine samples. 
Table 2 Ovarian reserve parameters among study population

\begin{tabular}{lllllllll}
\hline Parameters & A Mean \pm SD & G Mean \pm SD & Min & Q25 & Median & Q75 & Q95 & Max \\
\hline AFC $(\mathrm{n})$ & $12.73 \pm 8.94$ & $12.25 \pm 1.73$ & 1 & 8 & 11 & 20 & 30 & 40 \\
AMH $(\mathrm{ng} / \mathrm{ml})$ & $1.17 \pm 1.46$ & $1.21 \pm 1.4$ & 0.02 & 0.9 & 1.3 & 2.9 & 9.36 \\
FSH (IU/l) & $6.38 \pm 2.18$ & $6.00 \pm 1.43$ & 0.9 & 4.86 & 6.14 & 7.51 & 10.48 \\
E2 $(\mathrm{pg} / \mathrm{ml})$ & $93.74 \pm 16.63$ & $91.33 \pm 12.89$ & 75 & 83 & 95 & 120 & 180 & 200 \\
\hline
\end{tabular}

A Mean aritmetic mean, G Mean geometric mean, SD standard deviation, Min minimal value, Max maximum value, Q25 25 perentyl, Q75 75 percentyl, Q95 95 percentyl, $A M H$ Anti-Müllerian hormone, AFC antral follicle count, FSH follicle-stimulating hormone, E2 estradiol

\section{Urinary parabens concentration and ovarian reserve}

In multivariate linear regression models where the exposure variable was treated as a continuous variable only PP decrease AFC $(p=0.04), \mathrm{E}_{2}$ level $(p=0.04)$ and increase the FSH concentration $(p=0.028)$ (Table 6). MP, $\mathrm{EP}, \mathrm{BP}$ and $\mathrm{iBuP}$ were not associated any with parameters of ovarian reserve (AFC and the concentrations of $\mathrm{AMH}, \mathrm{FSH}$ and $\mathrm{E}_{2}$ ). The models were adjusted for age, smoking, BMI and initial infertility diagnosis.
Similar results were observed when the exposure variables were categorized. Exposure to PP in the third quartile (50th -75th] was negatively associated with antral follicle count $(p=0.048)$ and $\mathrm{E}_{2}$ concentrations $(p=0.03)$ and positively with FSH $(p=0.026)$ (Table 6).

\section{Discussion}

In the study, we found a relationship between urinary concentrations of parabens and parameters of ovarian

Table 3 Distribution of urinary parabens concentration in urine samples

\begin{tabular}{|c|c|c|c|c|c|c|c|c|c|}
\hline \multirow{2}{*}{$\begin{array}{l}\text { Parabens in urine } \\
(\mu \mathrm{g} / \mathrm{L})\end{array}$} & \multicolumn{9}{|l|}{ Statistics } \\
\hline & A Mean \pm SD & G Mean \pm SD & LOD & Q25 & Median & Q75 & Q95 & $\operatorname{Max}$ & $>\operatorname{LOD}(\%)$ \\
\hline \multicolumn{10}{|l|}{ First urine sample $\mathrm{N}=511$} \\
\hline MP & $198.91 \pm 224.37$ & $92.68 \pm 4.28$ & 0.5 & 37.69 & 119.74 & 280.89 & 688.12 & 1260.36 & 93.92 \\
\hline EP & $57.21 \pm 112.02$ & $11.28 \pm 7.00$ & 0.5 & 2.00 & 9.52 & 56.42 & 258.96 & 785.72 & 84.31 \\
\hline PP & $97.80 \pm 430.61$ & $16.20 \pm 6.33$ & 0.5 & 4.06 & 15.54 & 59.21 & 371.12 & 7193.09 & 84.11 \\
\hline $\mathrm{BP}$ & $10.13 \pm 20.22$ & $4.70 \pm 2.96$ & 1.0 & 1.99 & 3.95 & 8.60 & 40.89 & 202.43 & 64.12 \\
\hline iBuP & $5.19 \pm 6.53$ & $3.16 \pm 2.55$ & 1.0 & 1.35 & 2.47 & 6.07 & 19.06 & 34.95 & 10.60 \\
\hline$\sum$ Parabens (nmol/ml) & $176.61 \pm 158.75$ & $25.60 \pm 4.62$ & 0.5 & 9.42 & 30.24 & 82.24 & 275.63 & 1895.31 & \\
\hline \multicolumn{10}{|l|}{ SG adjusted ( $\mu \mathrm{g} / \mathrm{L})$} \\
\hline MP & $232.97 \pm 287.21$ & $107.93 \pm 4.39$ & 0.5 & 43.1 & 145.76 & 316.12 & 731.34 & 2922.30 & 93.92 \\
\hline$E P$ & $62.64 \pm 121.45$ & $12.90 \pm 7.04$ & 0.5 & 2.37 & 13.10 & 62.76 & 264.13 & 42.43 & 84.31 \\
\hline PP & $98.94 \pm 382.95$ & $18.67 \pm 6.25$ & 0.5 & 4.56 & 18.49 & 72.70 & 359.68 & 5394.81 & 84.11 \\
\hline $\mathrm{BP}$ & $10.90 \pm 21.58$ & $5.02 \pm 3.05$ & 1.0 & 2.27 & 4.29 & 9.73 & 37.21 & 197.77 & 64.12 \\
\hline iBuP & $4.61 \pm 5.54$ & $2.80 \pm 2.68$ & 1.0 & 1.24 & 2.53 & 4.86 & 15.38 & 30.92 & 10.60 \\
\hline \multicolumn{10}{|c|}{ Second urine sample $N=120$} \\
\hline MP & $116.62 \pm 154.42$ & $49.13 \pm 105.39$ & 0.5 & 19.08 & 61.22 & 154.14 & 216.85 & 993.87 & 90.83 \\
\hline EP & $33.91 \pm 71.06$ & $5.71 \pm 44.97$ & 0.5 & 1.19 & 3.51 & 24.09 & 37.21 & 391.51 & 71.67 \\
\hline PP & $32.91 \pm 71.06$ & $9.14 \pm 38.58$ & 0.5 & 2.44 & 9.86 & 25.65 & 42.11 & 504.93 & 70 \\
\hline $\mathrm{BP}$ & $9.44 \pm 30.90$ & $3.99 \pm 9.90$ & 1.0 & 1.90 & 3.43 & 7.76 & 9.21 & 235.34 & 47.5 \\
\hline$\sum$ Parabens (nmol/ml) & $48.22 \pm 81.86$ & $16.99 \pm 198.84$ & 0.5 & 6.16 & 4.88 & 52.91 & 76.34 & 531.41 & \\
\hline \multicolumn{10}{|l|}{ SG adjusted ( $\mu \mathrm{g} / \mathrm{L})$} \\
\hline MP & $149.84 \pm 207.56$ & $67.18 \pm 125.60$ & 0.5 & 24.20 & 91.16 & 204.18 & 312.78 & 1715.13 & 90.83 \\
\hline EP & $38.45 \pm 77.20$ & $7.85 \pm 8.85$ & 0.5 & 1.58 & 4.73 & 37.71 & 42.15 & 534.96 & 71.67 \\
\hline PP & $39.75 \pm 82.17$ & $46.49 \pm 52.13$ & 0.5 & 3.46 & 11.49 & 10.02 & 17.21 & 470.18 & 70 \\
\hline $\mathrm{BP}$ & $8.95 \pm 17.41$ & $4.74 \pm 7.73$ & 1.0 & 2.23 & 4.37 & 9.51 & 11.22 & 126.08 & 47.5 \\
\hline
\end{tabular}

A Mean artimetic mean, G Mean geometric mean, Q25 25 quartile, Q75 75 quartile, Q95 95 quartile, LOD limit of detection, MP methyl-paraben, EP ethyl-paraben, $P P$ propyl-paraben, BP butyl-paraben, iBuP izobuthyl-paraben 
Table 4 Spearman correlation between parabens

\begin{tabular}{|c|c|c|c|c|c|}
\hline \multicolumn{6}{|c|}{ First urine sample $(\boldsymbol{n}=511)$} \\
\hline & MP & EP & PP & iBuP & $\mathrm{BP}$ \\
\hline $\operatorname{MPr}(p)$ & 1 & & & & \\
\hline EP r (p) & $0.55(<\mathbf{0 . 0 0 1 )}$ & 1 & & & \\
\hline $\operatorname{PPr}(p)$ & $0.64(<\mathbf{0 . 0 0 1})$ & $0.41(<\mathbf{0 . 0 0 1})$ & 1 & & \\
\hline iBuPr (p) & $0.13(\mathbf{0 . 0 0 2 )}$ & $0.17(<\mathbf{0 . 0 0 1 )}$ & $0.16(<\mathbf{0 . 0 0 1 )}$ & 1 & \\
\hline $\operatorname{BPr}(p)$ & $0.30(<\mathbf{0 . 0 0 1 )}$ & $0.28(<0.001)$ & $0.28(<0.001)$ & $0.34(<0.001)$ & 1 \\
\hline \multicolumn{6}{|c|}{$\begin{array}{l}\text { Second urine } \\
\text { sample }(N=120)\end{array}$} \\
\hline & MP & EP & PP & $\mathrm{BP}$ & \\
\hline $\operatorname{MPr}(p)$ & 1 & & & & \\
\hline EP r (p) & $0.44(<\mathbf{0 . 0 0 1})$ & 1 & & & \\
\hline $\operatorname{PPr}(p)$ & $0.49(<\mathbf{0 . 0 0 1 )}$ & $0.37(<\mathbf{0 . 0 0 1 )}$ & 1 & & \\
\hline $\operatorname{BP} r(p)$ & $0.26(\mathbf{0 . 0 0 4 )}$ & $0.16(0.09)$ & $0.13(0.17)$ & 1 & \\
\hline
\end{tabular}

Note: $p p$ values, $r$ correlations coefficient, MP methyl-paraben, $E P$ ethylparaben, $P P$ propyl-paraben, $B P$ butyl-paraben, $i B u P$ izobuthyl-paraben

reserve. The statistically significant associations were observed between urinary concentrations of PP and decrease AFC, $E_{2}$ level and increase the FSH concentration.

To our knowledge, only one human study has investigated the association between urinary paraben concentrations and female ovarian reserve [13]. Our findings are in line with the study performed by Smith et al. (2013) [13] where a negative relationship between urinary PP and AFC was also found. Higher urinary PP was associated with a higher FSH. In this study PP concentrations in urine were associated with decrease antral follicle count, estradiol level and increased the FSH concentrations. Other examined parabens: MP, EP, BP and iBuP were not associated any with parameters of ovarian reserve (antral follicle count and the concentrations of $\mathrm{AMH}, \mathrm{FSH}$ and $\mathrm{E}_{2}$ ).

The relationship of PP with diminished ovarian reserve is consistent with animal data showing that the estrogenicity of parabens, and therefore the potential for reproductive toxicity, is greater in $\mathrm{PP}$ compared with MP $[7,8,23]$. Although the animal data also show that BP and $\mathrm{iBuP}$ is more estrogenic than PP or MP, we detected $\mathrm{BP}$ and $\mathrm{iBuP}$ less frequently. When the chemical was detected, urinary concentrations of BP were much lower than those of either PP or MP, which may explain the

Table 5 Correlations between parabens in two urine samples

\begin{tabular}{lll}
\hline Parabens & Coef (S1-S2) & $p($ S1-S2) \\
\hline MP & 0.31 & $\mathbf{0 . 0 0 1}$ \\
EP & 0.32 & $<\mathbf{0 . 0 0 1}$ \\
PP & 0.39 & $<\mathbf{0 . 0 0 1}$ \\
iBuP & No detected in the second urine sample \\
BP & 0.08 & 0.39 \\
\hline
\end{tabular}

$M P$ methyl-paraben, $E P$ ethyl-paraben, $P P$ propyl-paraben, $B P$ butyl-paraben, iBuP izobuthyl-paraben, $S 1$ first urine sample, $S 2$ second urine sample lack of an association of BP with markers of ovarian reserve. It is also possible that biological activity and mechanisms of action differ between the parabens.

The mechanism of the potential impact of nonpersisntant environmental factors such as parabens is associated with the roles of the aryl hydrocarbon receptor (AHR) and the estrogen receptor (ER) systems in ovarian reserve modulation. Environmental compounds are similar to the natural ligands and have the ability to bind to these receptors and have the potential to influence either the initial setting of ovarian reserve during development or the trajectory of ovarian reserve during adult life [24].

One of the predictors of women fertility is undoubtedly ovarian reserve, which could be used to determine the potential of female fecundity. Therefore, it is important that ovarian reserve is looked closely in studies on fertility. AFC is considered one of the best markers of ovarian reserve [25]. Additionally serum AMH level can be assessed regardless of pregnancy-attempts status and the measurements are not significantly affected by phase of menstrual cycle [26]. Baird and Steiner (2012) [26] suggest that this hormone should be investigated as an independent measure of fecundability in studies that focus on exposures hypothesized to target the ovary and is a potential tool in epidemiologic studies of female fertility.

Urinary concentrations of parabens in our study subjects were comparable to those reported in a national sample of US women in the fourth report of the $\mathrm{Na}$ tional Health and Nutrition Examination Survey (NHANES) with respect to PP (CDC 2017) [27]. Geometric mean concentrations recently reported in females participating in the NHANES 2011-2014 were $13.5 \mu \mathrm{g} / \mathrm{L}$ compared to $15.54 \mu \mathrm{g} / \mathrm{L}$ in the present study. The median urinary concentrations of MP, EP and BP were higher in our study than in NHANES $119.74 \mu \mathrm{g} / \mathrm{L}$ and $73.9 \mu \mathrm{g} / \mathrm{L}$ for $\mathrm{MP}, 9.52 \mu \mathrm{g} / \mathrm{L}$ and $1.60 \mu \mathrm{g} / \mathrm{L}$ for EP and $3.95 \mu \mathrm{g} / \mathrm{L}$ and $<$ LOD for BP respectively. Also the concentrations of parabens found in our study were higher than in the study performed among Tunisian women (urinary geometric mean concentrations of MP-30.1 ng/ $\mathrm{ml}$, EP-1.4 ng/ml, PP-2.0 ng/ml, BP-0.5 ng/ml) [28]. The urinary concentration of $\mathrm{BuP}$ was not measured in the US survey. The iBuP level was assessed in an urban community of Western Canada where the urinary concentrations were lower (median $0.22 \mu \mathrm{g} / \mathrm{L}$ ) than in the present study (median $2.47 \mu \mathrm{g} / \mathrm{L}$ ). The differences in the level of iBuP may be associated with the fact that in the study in Canada, the exposure assessment was performed among 11 participants [29].

To the best of our knowledge, this is the largest human study to date to evaluate the association between environmental exposure to parabens and parameters of ovarian reserve. The limitations is the cross-sectional design of this study which does not allow the inference of 
Table 6 The association between parabens and parameters of ovarian reserve- categorical variable

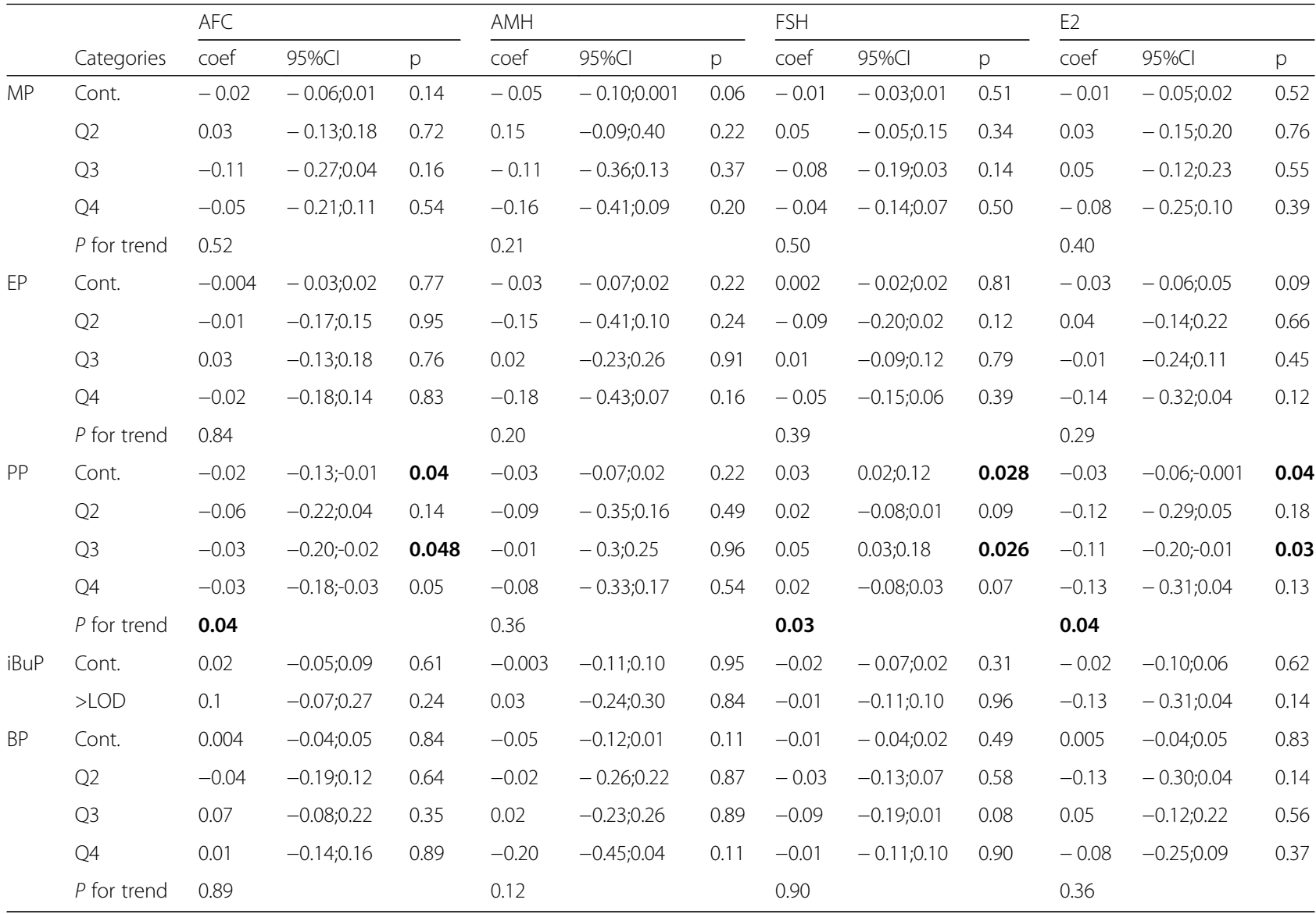

Model adjusted for: age (years), BMI $\left(\mathrm{kg} / \mathrm{m}^{2}\right)$, smoking (Yes/No) and initial infertility diagnosis. Parabens exposure in the model was based on the first urine sample $M P$ methyl-paraben, $E P$ ethyl-paraben, $P P$ propyl-paraben, $B P$ butyl-paraben, $i B u P$ izobuthyl-paraben

Reference groups 1. In case >LOD reference is $\angle \mathrm{LOD} ; 2$. In case Q2, Q3, Q4 reference is Q1; Cont.-continuous variable

Q1- 25 percentyl; Q2- (25-50] percentyl; Q3-(50-75] percentyl; Q4- > 75 percentyl

causal relationships and, consequently, reverse causality issues cannot be ruled out. Due to its design, it may not be possible to generalize our findings to women who are not seeking fertility evaluation. Additionally, we only have considered paraben exposure, but women are exposed to a wide range of environmental chemicals that may contribute to the mixture effect.

The strength of our study is the collection which include two urine samples. Although one urine sample may reasonably represent several months of exposure, collection of multiple samples should reduce exposure misclassification during the time period.

In addition, in the present study, all subjects were recruited in the same center, and all samples were collected and analyzed using a standardized protocol. Detailed questionnaire on demographics, medical and lifestyle risk factors received from the participants allowed for control of confounding variables in the statistical models. Since the present study was conducted among women recruited through an infertility clinic, it may limit the ability to generalize the results to the general population. On the other hand these findings may be of concern because of increased use of parabens that results in widespread exposure among the general population and lack of human epidemiologic studies. Further epidemiological studies will be helpful to better understand the effects of parabens on female fecundity.

In conclusion, we observed an inverse association between urinary concentrations of PP and decrease AFC and $E_{2}$ level. Additionally PP was positively associated with FSH in women attending a fertility center. Our findings could be suggestive that a chronic exposure to PP may potentially contributing to reduced fecundity and impair fertility. As this is one of the first study to investigate the potential effect of parabens on ovarian reserve further epidemiological studies with longer duration of observation are needed.

\section{Acknowledgments}

Not applicable.

Authors' contributions

Joanna Jurewicz was involved in study concept, design and data interpretation. Wojciech Hanke and Michał Radwan were involved data interpretation. Data analysis was performed by Paweł Kałużny. Joanna 
Jurewicz drafted the manuscript. Michał Radwan, Paweł Radwan, Anetta Karwacka were responsible for recruitment of women to the study and analysis of the parameters of ovarian reserve. Bartosz Wielgomas, Anna Klimowska were responsible for analysis of urinary level of parabens. All authors provided substantial intellectual contributions and approved the final version of manuscript.

\section{Funding}

This study was performed under the project "Exposure to widespread, environmental endocrine disrupting chemicals and ovarian reserve" supported by National Science Centre in Poland from grant no. UMO-2017/ 27/B/NZ7/01921.

\section{Availability of data and materials}

The datasets used and analyzed during the current study are available from the corresponding author on reasonable request.

\section{Ethics approval and consent to participate}

The Nofer Institute of Occupational Medicine Bioethical Committee Board approved the study (resolution no. 23/2014 and for the continuation: resolution no. 10/2018).

and written informed consent was obtained from all subjects before their participation.

\section{Consent for publication}

Not applicable.

\section{Competing interests}

The authors declare that they have no competing interests.

\section{Author details}

${ }^{1}$ Department of Environmental Epidemiology, Nofer Institute of Occupational Medicine, 8 Teresy St, 91-362 Lodz, Poland. 'Department of Gynecology and Reproduction, "Gameta" Hospital, 34/36 Rudzka St, 95-030 Rzgów, Poland. ${ }^{3}$ Faculty of Health Sciences, The State University of Applied Sciences in Plock, 2 Dabrowskiego Sq, 09-402 Plock, Poland. Department of Toxicology, Medical University of Gdańsk, 107 Hallera St, Gdańsk, Poland. ${ }^{5}$ Gyncare Clinic, 7 Chodkiewicz St, 02-593 Warsaw, Poland.

Received: 7 February 2019 Accepted: 20 February 2020

Published online: 02 March 2020

\section{References}

1. Andersen FA. Final amended report on the safety assessment of methylparaben, ethylparaben, propylparaben, isopropylparaben, butylparaben, isobutylparaben, and benzyl paraben as used in cosmetic products. Int J Toxicol. 2008:27(suppl 4):1-82.

2. Braun JM, Just AC, Williams PL, Smith KW, Calafat AM, Hauser R. Personal care product use and urinary phthalate metabolite and paraben concentrations during pregnancy among women from a fertility clinic. J Expo Sci Environ Epidemiol. 2014;24:459-66.

3. Soni MG, Carabin IG, Burdock GA. Safety assessment of esters of phydroxybenzoic acid (parabens). Food Chem Toxicol. 2005;43:985-1015.

4. Golden R, Gandy J, Vollmer G. A review of the endocrine activity of parabens and implications for potential risks to human health. Crit Rev Toxicol. 2005;35(5):435-58.

5. Okubo T, Yokoyama Y, Kano K, Kano I. ER-dependent estrogenic activity of parabens assessed by proliferation of human breast cancer MCF-7 cells and expression of ER alpha and PR. Food Chem Toxicol. 2001;39:1225-32.

6. Gomez E, Pillon A, Fenet H, Rosain D, Duchesne MJ, Nicolas JC, Balaguer P, Casellas C. Estrogenic activity of cosmetic components in reporter cell lines: parabens, UV screens, and musks. J Toxicol Environ Health A. 2005;68(4):239-51.

7. Routledge EJ, Parker J, Odum J, Ashby J, Sumpter JP. Some alkyl hydroxy benzoate preservatives (parabens) are estrogenic. Toxicol Appl Pharmacol. 1998;153(1):12-9.

8. Vo TT, Yoo YM, Choi KC, Jeung EB. Potential estrogenic effect(s) of parabens at the prepubertal stage of a postnatal female rat model. Reprod Toxicol. 2010;29(3):306-16.

9. Darbre PD, Harvey PW. Paraben esters: review of recent studies of endocrine toxicity, absorption, esterase and human exposure, and discussion of potential human health risks. J Appl Toxicol. 2008;28(5):56178.

10. Chen J, Ahn KC, Gee NA, Gee SJ, Hammock BD, Lasley BL. Antiandrogenic properties of parabens and other phenolic containing small molecules in personal care products. Toxicol Appl Pharmacol. 2007;221(3):278-84.

11. Taxvig C, Vinggaard AM, Hass U, Axelstad M, Boberg J, Hansen PR, Frederiksen $\mathrm{H}$, Nellemann C. Do parabens have the ability to interfere with steroidogenesis? Toxicol Sci. 2008;106(1):206-13.

12. Kang KS, Che JH, Ryu DY, Kim TW, Li GX, Lee YS. Decreased sperm number and motile activity on the F1 offspring maternally exposed to butyl phydroxybenzoic acid (butyl paraben). J Vet Med Sci. 2002;64:227-35.

13. Smith KW, Souter I, Dimitriadis I, Ehrlich S, Williams PL, Calafat AM, Hauser R. Urinary Paraben concentrations and ovarian aging among women from a fertility center. Environ Health Perspect. 2013;121:1299-305.

14. Dodge LE, Williams PL, Williams MA, Missmer SA, Toth TL, Calafat AM, Hauser R. Paternal urinary concentrations of parabens and other phenols in relation to reproductive outcomes among couples from a fertility clinic. Environ Health Perspect. 2015;123:665-71.

15. Mínguez-Alarcón L, Chiu YH, Messerlian C, Williams PL, Sabatini ME, Toth TL, Ford JB, Calafat AM, Hauser R. EARTH study team. Urinary paraben concentrations and in vitro fertilization outcomes among women from a fertility clinic. Fertil Steril. 2016;105(3):714-21.

16. Zegers-Hochschild F, Adamson GD, Dyer S, Racowsky C, de Mouzon J, Sokol R, Rienzi L, Sunde A, Schmidt L, Cooke ID, Simpson JL, van de Poel S. The international glossary on infertility and fertility care, 2017. Fertil Steril. 2017;108(3):393-406.

17. Broekmans FJ, de Ziegler D, Howles CM, Gougeon A, Trew G, Olivennes F. The antral follicle count: practical recommendations for better standardization. Fertil Steril. 2010;94(3):1044-51.

18. American Society for Reproductive Medicine Practice Committee. Testing and interpreting measure of ovarian reserve: a committee opinion. Fertil Steril. 2015;103:1407-15.

19. Lu D, Feng C, Wang D, Lin Y, Ip HS, She J, Xu Q, Wu C, Wang G, Zhou Z. Analysis of twenty phenolic compounds in human urine: hydrochloric acid hydrolysis, solid-phase extraction based on K2CO 3-treated silica, and gas chromatography tandem mass spectrometry. Anal Bioanal Chem. 2015; 407(14):4131-41.

20. Jurewicz J, Radwan M, Wielgomas B, Dziewirska E, Karwacka A, Klimowska A, Kałużny P, Radwan P, Bochenek M, Hanke W. Semen quality, sperm DNA damage, and the level of reproductive hormones in relation to urinary concentrations of parabens. J Occup Environ Med. 2017;59(11):1034-40.

21. Hornung RW, Reed LD. Estimation of average concentration in the presence of non-detectable values. Appl Occup Environ Hyg. 1990;5:46-51.

22. R Core Team. R: A language and environment for statistical computing. Vienna: R Foundation for Statistical Computing; 2016. http://www.R-project. org/. Accessed 20 Jan 2019.

23. Byford JR, Shaw LE, Drew MG, Pope GS, Sauer MJ, Darbre PD. Oestrogenic activity of parabens in MCF7 human breast cancer cells. J Steroid Biochem Mol Biol. 2002:80(1):49-60.

24. Richardson MC, Guo M, Fauser BC, Macklon NS. Environmental and developmental origins of ovarian reserve. Hum Reprod Update. 2014;20(3):353-69.

25. Rosen MP, Johnstone E, McCulloch CE, Schuh-Huerta SM, Sternfeld B, ReijoPera RA, Cedars MI. A characterization of the relationship of ovarian reserve markers with age. Fertil Steril. 2012;97(1):238-43.

26. Baird DD, Steiner AZ. Anti-Mullerian hormone: a potential new tool in epidemiologic studies of female fecundability. Am J Epidemiol. 2012;175(4):245-9.

27. Centers for Disease Control and Prevention. Fourth national report on human exposure to environmental chemicals (NHANES): United States Department of Health and Human Services; 2017. https://www.cdc.gov/ biomonitoring/pdf/FourthReport_UpdatedTables_Volume1_Jan2017.pdf. Accessed 30 Jan 2019.

28. Jiménez-Díaz I, Artacho-Cordón F, Vela-Soria F, Belhassen H, Arrebola JP, Fernández MF, Ghali R, Hedhili A, Olea N. Urinary levels of bisphenol a, benzophenones and parabens in Tunisian women: a pilot study. Sci Total Environ. 2016:562:81-8.

29. Genuis SJ, Birkholz D, Curtis L, Sandau C. Paraben levels in an urban community of Western Canada. ISRY Toxicol. 2013;507897:8. https://doi.org/ 10.1155/2013507897

\section{Publisher's Note}

Springer Nature remains neutral with regard to jurisdictional claims in published maps and institutional affiliations. 